www.jmscr.igmpublication.org

Impact Factor 5.84

Index Copernicus Value: 71.58

ISSN (e)-2347-176x ISSN (p) 2455-0450

crossref DOI: https://dx.doi.org/10.18535/jmscr/v5i12.51

Journal Of Medical Science And Clinical Research

\title{
Clinical Profile and Management of Lower G.I. Malignancies
}

\author{
Authors \\ Prof Dr Braja Mohan Mishra ${ }^{1}$, Prof Dr Bana Bihari Mishra, \\ Dr Balabhadra Samantaray ${ }^{3}$, Dr Dharbind Kumar Jha ${ }^{4}$ \\ ${ }^{1}$ Professor and HOD, ${ }^{2}$ Professor and Unit Head, ${ }^{3,4}$ Post Graduate Students \\ Department of General Surgery, Vimsar, Burla, Odisha, India \\ Email: balapapu4313@gmail.com, Mob: 9861839696
}

\begin{abstract}
Introduction: Lower GI malignancies though more common in the western part of world and are increasing in our country for the past decade. Colorectal cancer is the most common malignancy in the gastrointestinal tract. In the United States, colorectal cancer ranks fourth in terms of both gender-specific annual cancer incidence and cancer mortality (behind lung, prostate, and breast, respectively. Colonic tumors are important for two reasons: they are frequent and account for both a significant mortality rate as well as high cumulative health care costs. The sequence of events leading from a normal mucosa to a manifest cancer occurs through largely preventable precursor stages over the course of several years. Therefore this study predominantly focuses on the detection, management, and prevention of these conditions.

Aims and Objective

The aim of the study is,

1) To study the clinical presentation of lower GI malignancies, including the incidence of emergencies.

2) To study the macroscopic and histopathological types of lower GI malignancies.

3) To evaluate various types of surgeries for lower GI malignancies being performed.

Materials and Methods

- This study consists of patients admitted for the management of lower GI malignancies in Dept. of General Surgery, VSS Institute of Medical Science and Research, Burla, Odisha.

- Period of Study - November 2015 to October 2017.

- On admission all the patients were subjected to basic blood investigations, Test for fecal occult blood, USG Abdomen, Barium studies, CT abdomen and UGI scopy.

- Following clinical and proctoscopic examination, Colonoscopy was done for all patients - except for emergency cases, biopsies were taken.

- Bowel preparation was done preoperatively using plain oral fluids, and PEG preparation - the day before surgery.

- Per operative findings regarding peritoneal implants, liver secondaries, peritoneal implants and tumour invasion to the nearby structures were noted.

- Post operative course was closely observed until the first follow up visit.

- Patients with permanent colostomy were followed up for colostomy care.

Observation: Results are analysed using suitable statistical tables, graphs and methods.

Conclusion: To conclude, any patient above 40 years of age, when complaints of altered bowel habits or bleeding per rectum, every effort should be made thoroughly to investigate him to find out if he harbors malignancy of lower GI tract and the goal of treatment should be to either cure the disease or to prevent the sequele of disease there by reducing morbidity and mortality.
\end{abstract}




\section{Introduction}

Lower GI malignancies though more common in the western part of world and are increasing in our country for the past decade. Few topics in cancer research have more interest in the recent discovery of identifiable genetic defect in patients with inherited as well as sporadic form of colorectal carcinoma. The ideal goal of treatment in lower GI malignancies is the eradication of disease with preservation of anatomic\& physiological function. In the period between 1975 and 2006, the surveillance, epidemiology and End Results (SEER) Registry of the National Cancer Institute (NCI) shows a gradual decline in all cases of colorectal cancer in the United States from 69.7 to 50.6 cases per $100,000 .{ }^{9}$ However, although these numbers reflect the trend in Caucasians, the incidence of colorectal cancer in the United States for African Americans has remained at the same level of 59.3-61.5 cases per 100,000 individuals. African American males therefore now represent the ethnic subgroup with the higher risk. ${ }^{10,11}$.

Colonic tumors are important for two reasons: they are frequent and account for both a significant mortality rate as well as high cumulative health care costs. The sequence of events leading from a normal mucosa to a manifest cancer occurs through largely preventable precursor stages over the course of several years. Therefore this study predominantly focuses on the detection, management, and prevention of these conditions.

Colorectal cancer is the most common malignancy in the gastrointestinal tract. In the United States, colorectal cancer ranks fourth in terms of both gender-specific annual cancer incidence and cancer mortality (behind lung, prostate, and breast, respectively) ${ }^{4}$. With an estimated 146.970 newly diagnosed cases, this disease will be responsible for an estimated 49,920 deaths or 10$15 \%$ of cancer related deaths in the year $2009 ., 5$ The lifetime risk of approximately $6 \%$ in our Western civilization means that 1 in 18 individuals of the general population will be affected by colorectal cancer and many more by polyps, making it an important public health issue. ${ }^{6}$ Worldwide, colorectal cancer shows larger geographical differences, with a crude incidence of 6.5/7.7 cases per 100,000 females/males in less developed areas as compared to 50.9/60.8 in more developed regions. ${ }^{7}$

The colorectal cancer incidence has evolved in recent years to an overall predominance of males who represent in $51.4 \%$ of the cases.4.8 Rectal cancer is more frequent in females, resulting in almost identical overall mortality rates for both genders. ${ }^{4}$ The incidence of colorectal cancer in females is 44.8 per 100,000 and in males 61.2. Regardless of ethnicity, there is an age-dependent increase in incidence with each decade starting at age of 40 years, and the mean age at presentation is around 70-75 years.

Adenocarcinoma of the rectum accounts for nearly $30 \%$ of these cancers. This translates into 41,000 new diagnoses of rectal cancer each year and greater than 10,000 deaths attributable to this disease within the same time period.

More recently, local excision is being combined with neoadjuvant and adjuvant chemoradiotherapy to maximize local control with a minimally invasive approach.

There are evidences that neoplastic disease has affected humans since prehistoric times. Mummies from pre - Columbian, Peru of 2400 years ago as well as Egyptian mummies from 3000 B.C. have metastatic skeletal deposits. It was Hippocratic (460 - 370 B.C.) who first proposed a theoretical framework to explain cancer invasion. The cellular etiology of cancer was first described by Johannes Peter Muller in 1828. The following year Joseph Calrude Recaemer proposed that invasion and distant spread were the result of translocation of cells and he coined the term metastasis. The first successful resection of colonic growth was performed by Reynoard Lyons in 1823.

After Billroth, Czerny and Mickulicz, the pioneers in abdominal surgery familiarized, the technique of intestinal resection and anastomosis \& increasing number of colonic resections were 
attempted. The combined operation involving abdominal and perineal phases for excision of the rectum was first performed by Czerny (1883). But it was undoubtedly the work of Emest Miles (1908) that established the abdominoperineal operation.

Cuthberk Dukes (1935) classified carcinoma of rectum into 3 stages and explaining macroscopic variations 1 . These are widely used by pathologists with minimal changes even now for colorectal cancer staging. Paul of Liverpool (1895) and Mikulicz of Brestan (1903) devised extra peritoneal resection of carcinoma colon and popularized the technique in America.

Halstead (1895), Shoemaker (1921) Ranken (1928) and Wangenstein (1940) described various methods of anastomosis by which it was hoped to carry out resection and anastomosis in an entirely sterile manner without opening the bowel lumen till union was completed. But it was later pointed out by Moyhnian that the factor responsible for sepsis is not contamination during the operation itself but subsequent leakage.

Whipple (1931) and Turner (1937) favoured intraperitoneal resection with temporary caecostomy in order to relive the tension on the suture lines. Devine (1931) developed preliminary defunctioning colostomy which helped mechanical cleansing of the distal bowel.

After advent of strong intestinal antiseptics, reliance was placed on them entirely and a primary colostomy was entirely omitted. Lloyd Davis Morgan and Yollinger (1953) carried out resection with immediate anastomosis without any form of proximal decompression. In their series of 109 cases, there were only 3 postoperative deaths and none of them was due to sepsis.

In recent years, the trend is towards preparation with mechanical cleansing using balanced salt solutions containing osmotic purgatives in them with antibiotics, orally or IV 24 hour. This requires only single day preoperative preparation ${ }^{16}$.

Surgical resection remains the mainstay of treatment for Lower GI malignancies ${ }^{2}$. Radiotherapy and chemotherapy are used as adjuvant therapeutic options. Turnball at the Cleveland clinic recommended a no touch technique in which vascular and mesenteric division was first undertaken, thereby isolating the tumour.

The role of gene and their abnormality are being studied extensively and has given us the adenoma to carcinoma model due to accumulation of various genetic defects in the form of deletion, translocation etc. These may help us to find appropriate diagnostic tool to look for such aberration early, preventing cancer progression..

Colorectal surgery has advanced a lot with introduction of endo GIA staplers. Especially for sphincter saving procedures for carcinoma rectum31 with the advent of the laparoscope, laparoscopy assisted resection procedures are also being carried out ${ }^{13}$.

\section{Aims and Objective}

\section{The aim of the study is,}

1) To study the clinical presentation of lower GI malignancies, including the incidence of emergencies.

2) To study the macroscopic and histopathological types of lower GI malignancies.

3) To evaluate various types of surgeries for lower GI malignancies being performed.

\section{Materials and Methods}

- This study consists of patients admitted for the management of lower GI malignancies in Dept. of General Surgery, VSS Institute of Medical Science and Research, Burla, Odisha.

- Period of Study - November 2015 to October 2017.

- On admission all the patients were subjected to basic blood investigations, Test for fecal occult blood, USG Abdomen, Barium studies, CT abdomen and UGI scopy.

- Following clinical and proctoscopic examination, Colonoscopy was done for 
all patients - except for emergency cases , biopsies were taken.

- Bowel preparation was done preoperatively using plain oral fluids, and PEG preparation - the day before surgery.

O Per operative findings regarding peritoneal implants, liver secondaries, peritoneal implants and tumour invasion to the nearby structures were noted.

- Post operative course was closely observed until the first follow upvisit.

- Patients with permanent colostomy were followed up forcolostomy care.

\section{Observations and Discussion}

In this series of 80 cases of lower GI malignancies the following observations were made.

\section{Risk Factors}

\section{Diet}

Only 5 of the 80 patients were pure vegetarians. The majority of patients were illiterate; they could not specify the exact dietary constituents. But most patients gave history of consumption of fat and spicy food, fiber intake was moderately adequate in most patients.

\section{Tobacco}

50 patients out of 80 were using tobacco in some form or other. All the male patients except 5 were regular smokers of beedi or cigarettes. 25 out of 35 female patients were using tobacco in the form of tobacco, pan masala etc ${ }^{41}$.

\section{Incidence}

Age

Most of the cases were from older age group. Maximum incidence was in the sixth decade i.e. 34 cases in the age group $51-60$ yrs 14 .

\section{Table - 1 Sex Incidence}

\begin{tabular}{|l|c|c|}
\hline Gender & No. of case & Percentage \\
\hline Male & 45 & $56.25 \%$ \\
\hline Female & 35 & $43.75 \%$ \\
\hline
\end{tabular}

$\mathrm{M}: \mathrm{F}=45.35=1.28: 1$

\section{Sex}

Incidence was relatively more in males. M:F ratio in this series was 1.28:1. Incidence was nearly equal in rectal carcinoma with slight male preponderance in other site carcinomas 4 .

Table - 2 Age Incidence

\begin{tabular}{|l|c|c|c|c|}
\hline Range & Male & Female & Total & Percentage \\
\hline $21-30$ & 1 & 1 & 2 & 2.50 \\
\hline $31-40$ & 6 & 6 & 12 & 15.0 \\
\hline $41-50$ & 7 & 7 & 14 & 17.5 \\
\hline $51-60$ & 18 & 16 & 34 & 42.50 \\
\hline $61-70$ & 9 & 5 & 14 & 17.5 \\
\hline$>71$ & 4 & 0 & 4 & 5.0 \\
\hline Total & 45 & 35 & 80 & 100 \\
\hline
\end{tabular}

\section{Site}

Carcinoma rectum accounted for majority of cases. In 80 patients, 35 were carcinoma of rectum $(43.75 \%)$. The distribution of tumour in the other sites in the decreasing order of frequency were as follows., Small intestine 3, Colon 32, Rectum including Rectosigmoid junction 35, anal canal 14 , each.

48 out of 78 were left sided lesions.

Mode of Presentation:

Majority of the patients though had symptoms for some time, tend to ignore them and presented at late stages.

15 of the cases in this series presented as acute emergencies (18.75\%). 10 of them presented with obstructive features. Out of which 5were acute or chronic bowel obstruction. 3 patients presented with features of bowel perforation with peritonitis 50 .

Majority of the cases of right sided colonic tumours had symptoms of altered bowel habits, increasing constipation, bleeding per rectum, being the major complaint. Some patients presented with spurious diarrhea. Majority of bleeding per rectum were seen in rectum and sigmoid lesions .Pain was relatively late symptom. Abdominal lump was presented in 5 cases of rectosigmoid growth. 
Table $-\mathbf{3}$ Site Incidence

\begin{tabular}{|l|l|l|l|l|}
\hline Site & Male & Female & Total & Percentage \\
\hline Right Sided Tumour & 10 & 6 & 16 & 20.00 \\
\hline Left Sided Tumour & 35 & 12 & 47 & 58.75 \\
\hline Anal Canal & 9 & 6 & 15 & 18.75 \\
\hline
\end{tabular}

Table - 4 Site Incidence

\begin{tabular}{|l|c|c|c|c|}
\hline Site & Male & Female & Total & Percentage \\
\hline Jejunum \& ileum & 2 & 1 & 3 & 3.75 \\
\hline Caecum & 3 & 1 & 4 & 5.0 \\
\hline Ascending Colon & 2 & 2 & 4 & 5.0 \\
\hline Hepatic Flexure & 1 & 1 & 2 & 2.5 \\
\hline Transverse Colon & 1 & 2 & 3 & 3.75 \\
\hline Splenic Flexure & 1 & 2 & 3 & 3.75 \\
\hline Descending Colon & 2 & 3 & 5 & 6.25 \\
\hline Sigmoid Colon & 5 & 2 & 7 & 8.75 \\
\hline Rectosigmoid Junction & 9 & 6 & 15 & 18.75 \\
\hline Rectum & 11 & 9 & 20 & 25 \\
\hline Anal Canal & 8 & 6 & 14 & 17.5 \\
\hline Total & 45 & 35 & 80 & 100 \\
\hline
\end{tabular}

Table - 5 Lower GI Malignancies sign and Symptoms in the Series

\begin{tabular}{|c|c|c|c|c|c|c|}
\hline No. of Cases & 声志 & $\begin{array}{l}\frac{0}{0} \\
\dot{u} \\
\dot{4}\end{array}$ & $\begin{array}{l}\frac{0}{0} \\
\dot{0} \\
\dot{0}\end{array}$ & $\frac{0}{0}$ & U & $\begin{array}{c}\text { Rectum/ } \\
\text { Anal } \\
\text { Canal }\end{array}$ \\
\hline No. of Cases & 3 & 10 & 8 & 3 & 7 & 49 \\
\hline \multicolumn{7}{|l|}{ Signs / Symptoms } \\
\hline Pain & 2 & 9 & 8 & 3 & 5 & 20 \\
\hline Altered Bowel habits & 1 & 3 & 8 & 1 & 6 & 18 \\
\hline Bleeding per rectum & - & 4 & 5 & - & 4 & 18 \\
\hline Mucus per rectum & - & - & 8 & - & 4 & 16 \\
\hline Tenesmus & - & - & 8 & 2 & 3 & 14 \\
\hline Lump Abdomen & - & - & - & - & 3 & 2 \\
\hline Hepatomegaly & - & 2 & - & - & 3 & 3 \\
\hline Weight Loss & 3 & 9 & 8 & 3 & 6 & 22 \\
\hline Lassitude & 1 & 8 & 7 & 4 & 4 & 18 \\
\hline Anemia & 2 & 8 & 8 & 2 & 4 & 20 \\
\hline Acute Obstruction & 1 & 1 & 2 & - & 4 & 10 \\
\hline Peritonitis & - & - & 1 & 1 & 1 & 2 \\
\hline
\end{tabular}

Rectal growth was palpated in most cases of carcinoma rectum on per rectal examination.

Transverse colon growth presented with pain abdomen with typical history of diarrhoea alternating with constipation. Anemia, anorexia and progressive loss of weight was present in majority of cases at all sites.

12 patients presented with symptoms of metastasis / disseminated disease. 3 presented with skeletal metastases mainly in lumbo dorsal spine, out of which one presented with paraplegia. 10 cases presented with hepatomegaly, one patient presented with cough, haemoptysis, with multiple lung metastases.

\section{Diagnosis}

In this series, diagnosing cases of carcinoma of rectum \& analcanal was not a problem due to late presentation in most of the cases. One case of left colon growth perforation was missed due to extensive peritonitis with adhesion treated with 
conservative management. Right sided growth tend to present as mass and left sided growth with features of mass or obstruction \& most of rectal growths were palpated except fora few. Proctoscopic examination was done followed by tests for fecal occult blood. USG Abdomen \& CT Abdomen was done for all cases \&initial phase of the disease was studied. Colonoscopy was done for allcases, except emergency cases \& biopsies taken from the lesions under vision or from suspected areas. Contrast studies with Barium ,i.e., Bariummeal or Barium enema was done. CEA levels were done for 3 cases, levels were raised in all three cases, average $39 \mathrm{ng} / \mathrm{ml}$.

Pathology and Stage:

Most of the rectosigmoid and left sided growths were either annular and stenosing or ulcerative with infiltration type. Almost all cases of carcinoma rectum were of ulcerative type. 3 sigmoid growth showed infiltration into surrounding viscera. 2 cases of carcinoma rectum presented with posterior vaginal wall infiltration. One patient presented with $\mathrm{B} / \mathrm{L}$ hydronephrosis due to ureteric compression.

Table - 6 Histopathology

\begin{tabular}{|l|c|c|}
\hline Sl. No. & Types of CA & No. of cases \\
\hline 1 & Adeno Carcinoma & 64 \\
\hline 2 & $\begin{array}{c}\text { Squamous Carcinoma } \\
\text { (Anal Canal ) }\end{array}$ & 12 \\
\hline 3 & $\begin{array}{c}\text { Malignant Melanoma } \\
\text { (Anal Canal ) }\end{array}$ \\
\hline
\end{tabular}

Table - 7 Staging - Colon \& Rectum

\begin{tabular}{|l|c|c|c|c|}
\hline Stage & Male & Female & Total & Percentage \\
\hline A & 0 & 1 & 1 & 1.61 \\
\hline B & 8 & 9 & 17 & 27.41 \\
\hline C & 10 & 13 & 23 & 37.09 \\
\hline D & 14 & 7 & 21 & 33.87 \\
\hline TOTAL & 32 & 30 & 62 & 100 \\
\hline
\end{tabular}

Majority of right sided growths were polypoidal or cauliflower like growths. 1 hepatic flexure growth was found to infiltrate into abdominal wall. 1 case of multiple polyposis coli with rectal adenocarcinoma infiltrating into bladder was diagnosed 25. 2 cases of synchronous tumour found, one was synchronous rectal carcinoma and transverse colon growth. While the other was synchronous gastric carcinoma (antrum) and colonic carcinoma.

\section{Staging: (Colon \& Rectum)}

Only 1 case presented in Duke Stage A (1.61\%), 17 were in Stage B $(27.41 \%), 23$ were Stage C (37.09\%), 21 in Stage D (33.87\%). Out of 12 disseminated malignancies 10 had multiple liver metastases. While two had dorsolumbar spine metastasis. One patient presented with multiple lung secondaries. Two presented with peritoneal metastasis in the form of nodules.

\section{Grading}

Moderately differentiated tumour predominated. 45 out of 80 cases belonged to this (56.25\%), 25 cases were well differentiated $(31.25 \%)$ and 10 cases were poorly differentiated $(12.50 \%)$ type.

\section{Treatment Adopted}

Surgical resection in the form of either curative or palliative resection or palliative bypass / colostomy was attempted on all patients except 10. In these 10, 4 refused surgery and were treated with CT/RT while remaining went against medical advice.

\section{Emergency Cases}

15 patients presenting as emergencies were taken up., 5 patients had perforation with peritonitis. One case of descending colon, 3 cases rectosigmoid junction growth and one carcinoma rectum.

The first has presented with perforation near the proximal margin of growth treated with transverse loop colostomy and underwent electivere section and anastomosis. One rectal carcinoma presented with caecal perforation treated with ileostomy and elective APR later.

12 cases presenting with bowel obstruction were taken up for emergency surgery 20. Out of 6 rectal growths 3 were inoperable, treatedwith Hartmann procedure with end colostomy. (Fig.29,30). Remaining were treated with temporary defunctioning colostomy with elective APR later (Fig.31,32). Out of 3 growths in rectosigmoid / sigmoid colon, 2 were inoperable with extensive local infiltration, treated by transverse loop 
colostomy. While in one resection (palliative) done with Hartmann's procedure. One caecal growth was inoperable which was treated by ileotransverse anastomosis.(Fig.16)

\section{Elective Cases}

50 patients were treated with elective surgery in whom 25 rectal carcinomas underwent curative APR with 3 cases treated with anterior resection with colo anal anastomosis ${ }^{27}$. (Fig.21,22). 4 cases underwent Haartmann's procedure. 3 left colon growth were treated with left hemicolectomy (Fig.19,20) and 9 patients underwent right hemicolectomy (Fig.17,18),, with 2 extended hemicolectomies for transverse colon growth, other included cancer caecum and ascending colon. Circular staplers were used for 4 cases and sphincter saving surgery was performed. (Fig.28).

Table -7

\begin{tabular}{|l|l|l|}
\hline Sl. No. & Surgery & Numbers \\
\hline 1 & Elective Cases & 50 \\
\hline 2 & Emergency cases & 15 \\
\hline
\end{tabular}

Table - 8 Curative Resection

\begin{tabular}{|l|c|}
\hline Surgery Done & No. of case \\
\hline Right Hemicolectomy & 10 \\
\hline Left Hemicolectomy & 5 \\
\hline Segmental Resection / Anastomosis & 10 \\
\hline Anterior Resection & 5 \\
\hline APR & 25 \\
\hline
\end{tabular}

Segmental resections were done in 7 cases which, were for jejunoileal growth. rectosigmoid growth $\&$ transverse colon growth.

Table -9 CT / RT

\begin{tabular}{|l|c|}
\hline & No. of cases \\
\hline Adjuvent (ADJ) & 50 \\
\hline Neo Adjuvent (NDJ) & 2 \\
\hline Chemoradiotherapy & 15 \\
\hline
\end{tabular}

\section{Adjuvant Therapy}

The following Regimen was used:

I. CA Colon

Inj.Oxaliplatin $100 \mathrm{mg} / \mathrm{m} 2$ from D 1 to D 3

Inj. 5 FU $750 \mathrm{mg}$ from D 1 to D 3

Inj. Leucoverin $30 \mathrm{mg}$ from D 1 to D 3

The above drugs were given for six cycles.
II. CA Rectum

The above drugs were given for two cycles followed by radiotherapy and then 2 more cycles of chemotherapy.

III. CA Anal Canal

Inj. Mitomycin C $12 \mathrm{mg}$ on D1

Inj. 5 FU $750 \mathrm{mg}$ on D1 to D4. With concurrent RT (6000 cGy @200 cGy/ day).

48 cases received adjuvant chemotherapy. 8 people refused further adjuvant therapy. Radiotherapy was given preoperatively to one patient and later underwent Haartmann's procedure for (carcinoma rectum) obstruction.

\section{Complications}

Significant post operative complications included anastamotic leak, faecal fistulae occurred in 7 patients. Surgical site infection occurred in 9 patients which were treated accordingly. General complications like post operative respiratory infection, uraemia, electrolyte imbalance were found in 12 patients. Most of them belonged to older age group with associated diabetes mellitus and poor general status. One case of stapleranastomosis had leak which needed revision.

\section{Follow up}

Follow up was average with most patients failing to turn up after $3-6$ cycles of chemotherapy, 10 patients attended the clinic for a long time in the follow up period in this study on an average of 20 months and1 patient was followed up for 28 months which was the longest. 8 patients developed multiple hepatic metastases during follow up. While 3 patients had local recurrence, 18 patients had regular follow up with repeat USG and basic blood investigations being normal.

\section{Summary}

The primary goal of surgical treatment for rectal cancer is complete eradication of the primary tumor along with the adjacent mesorectal tissue and the superior hemorrhoidal artery pedicle. although reestablishment of bowel continuity at the time of surgery has become routine, cancer removal should not be compromised in an attempt to avoid a permanent colostomy. 
For tumors located in the extraperitoneal rectum, resection margins are limited by the bony confines of the pelvis and the proximity of the bladder, prostate, and seminal vesicles in men and vagina in women. Although locoreginal recurrence may be inevitable, local recurrence, cure, mortality, anastomotic leaks, and colostomy rates after rectal cancer surgery are related to surgical technique as well as to the experience and volume of the individual surgeon and institution.

Local recurrence of rectal adenocarcinoma is seen in up to $30 \%$ of patients, although recurrence may be seen at the distal margin of the anastomosis, most develop from residual cancer on the pelvic wall the time course for recurrences to present through the anastomosis is approximately 18 months by their nature, these tumors are fixed to the pelvic wall and surrounding viscera, they cause significant symptoms, such as intractable pelvic pain, bleeding, cramping or constipation, urinary tract dysfunction, and chronic pelvic sepsis.

When patients present with these symptoms or with a rising CEA level, a workup including CT scan of the abdomen and pelvis, ERUS, MRI of the pelvis, and PET scan may be helpful, a careful pelvic examination is mandatory. A biopsy, either via sigmoidoscopy or CT-guided, should be used to confirm the diagnosis pathologically, if external radiation has not been used before, it should be considered. the surgeon should review the imaging studies and determine which organs are involved, such as the vagina, uterus, prostate, bladder, sacrum, and small intestine, which will require en bloc resection.

Screening of colorectal cancer is effective in reducing the overall mortality from colorectal ca. presumably by discovery of tumour at earlier \& thus more curable resection surgery with tumour free margin can be done in an early TNM staging where disease is not in advanced stage . in this aspect it is ideal disease for directed screening. Mechanical cleaning of the colon has recently been deemphasized as necessary part of bowel preparation of patient of colon resection while there is no evidence to support and increase risk of Anastomotic leak or infectious complication for elective colon resection in stool filled bowled, in fact patient have often had some form of amended bowel cleaning by not eating solid foods for a day or more taking some laxative \& using disposable enema. This particularly true for left side colon.

\section{Conclusion}

1) Most patients were non vegetarians taking a high fat diet. But no definite evidence of diet as a risk factor could be identified.

2) Commonest age group of Lower GI Malignancies was on the 6thdecade.

3) Incidence was higher in males, $M: F$ was $1.28: 1$

4) Carcinoma Rectum was the most commonest site of large bowel $(43.75 \%)$ in the series.

5) 15 cases presented with acute emergency in the form of bowel obstruction or perforation.( $18.75 \%$ )

6) Use of Staplers have enabled Sphincter saving surgeries to be done\& avoids a Permanent Colostomy.

7) To conclude, any patient above 40 years of age, when complaints of altered bowel habits or bleeding per rectum, every effort should be made thoroughly to investigate him to find out if he harbors malignancy of lower GI tract.

8) Incidence of left side GI malignancies are of more 47 (58.75\%)

9) Histopathologically adeno carcinoma is 64 $(80 \%)$

10) In duke staging stage $\mathrm{C}-37.09 \%$, stage $\mathrm{D}$ $-33.87 \%$, stage B $-27.41 \%$.

\section{References}

1. Short Practice of Surgery. Bailey \& Love 26th Edition (P. 1153 - 1272).

2. Maingot's Abdominal Operations 12th Edition (P. 479 to 757 ).

3. Sabiston Textbook of Surgery 19th Edition Vol. 2 (P.1219 to $1241 \& 1323$ - 1573). 
4. Schwartz's Principles of Surgery 10th Edition. (P. 1017 to 1137)

5. Hamilton Bailey's Emergency Surgery 13th Edition (P. 393 - 446).

6. Mastery of Surgery Fourth Edition, RoberJ.Baker, Joseph E.Fischer, (P. 1399 1689).

7. Principles of Oncology - Devita Hellman, Rosenberg (P. 1036 - 1135).

8. Oxford Textbook of Surgery. 2nd Edition (P. 1345 - 1611).

9. Principles and Management of Cancer - A Practical Guide (RanajitSen) (P. 154 157).

10. UCSF Medical Centre TNM Staging of Colon \& Rectum.

11. Recent Advances in Surgery (26) 2003 (Wendy Atkin, John Marshover) (P. 111 120)

12. Recent Advances in Surgery for Rectal Cancer (9) 2004. PJ Shukla, HA Kanhex SV Shrikand (P. 263 - 272)

13. Sphincter Saving Surgery for Cancer Lower Rectum with Special Emphasis on Abdominosacral Resection (Recent Advances in Surgery - 9) Dhananjaya Sharma (P. 275 - 282)

14. Current Surgical Diagnosis and Treatment - 12th Edition. 2006 (P. 652 - 763)

15. Gastroenterology Clinics of North America - 2007 (Colorectal Cancer in IBD AIN \& other Neoplastic Precursor lesions of the Anal Canal and Perianal region)

16. Randomised Clinical trial of effect of Synbiotics, neomycin \& mechanical bowel preparation on intestinal barrier function in patients undergoing colectomy. - British Journal of Surgery 2007-94 (546 - 554)

17. Local Excision of rectal tumours by transanal endoscopic microsurgery British Journal of Surgery 2007 - 94 (627 - 633)

18. Early introduction of laparoscopic sigmoid colectomy during residency. - British
Journal of Surgery 2007 - 94 (P. 634 641)

19. Colorectal Cancer - Clinical Review (Anne B Ballinger, Clive Angiansah) (P.715 - 718) British Medical Journal Oct 2007 Vol. 335

20. Signet ring cell $\mathrm{Ca}$ of Appendix presenting with intestinal Obstruction. - Indian Journal of Surgery Feb 2007 Vol. 69, (P. 22-24)

21. Optical Adjuncts for Enhanced Colonoscopic Diagnosis. - British Journal of Surgery 2007; 94 (P. 6 - 16)

22. Role of Circulating tumour cells in predicting recurrence after excision of primary colorectal carcinoma - British Journal of Surgery 2007. 94 (P. 96 - 105)

23. Impact of Radiotherapy on local recurrence of rectal cancer in Norway. British Journal of Surgery 2007 - 94 (P. 113 - 118)

24. Multicentric Randomised clinical trial of mechanical bowel preparation in elective colonic resection. British Journal of Surgery 2007; 94 (P. 689 - 695)

25. Young Age Colorectal Cancer and Identification of Hereditary NonPolyposis Colorectal Cancer Cohorts. British Journal of Surgery 2007; 94 (P. 1055 - 1056)

26. Size of Surgical Margin does not influence recurrence rates after curative liver resection for colorectal cancer liver metastases - British Journal of Surgery 2007. 94 (P. 1133 - 1138)

27. Oncological outcome of Ultra low coloanal anastomosis with and without intersphincteric resection for low rectal adenocarcinoma - British Journal of Surgery 2007. 94 (341 - 345)

28. Leptin acts as a mitogenic and antiapoptotic factor for Colonic cancer cells. - British Journal of Surgery 2007. 94 (P. 346 - 354) 
29. Clinical risk score predicts yield of staging laparoscopy in patients with colorectal liver metastases. - British Journal of Surgery 2007.94 (P. $855-859$

30. Role of Ultrasonography in the detection of unresectable recurrence after lobectomy for colorectal liver metastases. - British Journal of Surgery 2007. 94 (P. 1403 1407)

31. Population based study of local surgery for rectal cancer - British Journal of Surgery 2007. 94 (P. 1421 - 1426)

32. Prediction of Lateral Pelvic node involvement in low rectal cancer by conventional Computed tomography. British Journal of Surgery 2007. 94 (P. 1014 - 1019)

33. Immuno Histochemical Staining for Mismatch repair proteins and its reliance in the diagnosis of HNPCC - British Journal of Surgery 2007.94 (P. 1020 1027)

34. Preoperative but not postoperative systemic Inflammatory response correlates with survival in colorectal cancer. - British Journal of Surgery 2007.94 (P. 1028 1032)

35. Inspired Supplemental Oxygen reduces markers of oxidative stress during elective colon surgery - British Journal of Surgery 2007.94 (P. 475 - 477).

36. A Protocol in not enough to implement an enhanced recovery programme for colorectal resection - British Journal of Surgery 2007; 94 (P. 224 - 231)

37. Extended abdominoperineal resection with gluteus maximus flap reconstruction of the pelvic floor for rectal cancer. - British Journal of Surgery 2007.94 (P. 232 - 238)

38. Clinicopathological significance of microscopic abscess formation at the invasive margin of advanced low rectal cancer - British Journal of Surgery 2007 (P. 239 - 243)
39. Impact of surgeon volume and specialization on short term outcomes in colorectal cancer surgery - British Journal of Surgery 2007.94 (P. 880 - 889)

40. Differences in Patient post operative and long term outcomes between obstructive and perforated colonic cancer. (Dept. of Surgery, Colorectal Unit, University of Barcelona, Spain) Pub Med.

41. 4Quality of Life Assessments in Colorectal Surgery (Jess.P. Hillaned Hospital, KirurgiskKlinik Pub Med.)

42. Pathologic Basis of Disease - Robbins 7th Edition. P 828 - 875

43. Principles of Internal Medicine - Harrison - 16th Edition (P. 1763 - 1808)

44. A.S.I. Text Book of Surgery 2003 Edition (P. 431 - 523)

45. Essential Surgical Practice by Cushierie (Third Edition) (P. 1297 - 1408)

46. Atlas of Operative Surgery - Zollingher (P. 363 - 478)

47. American College of Surgeons Textbook of Surgery(Principles \& Practice) 2005 Edition (P. 403 - 755)

48. Textbook of Radiology \& Imaging. Vol 1.David Sufton 7th Edition. (P. 615 - 691)

49. Clinicopathological characteristics of colonic carcinoma in relation to localization and histologic type. (Article in Serbian - Pub Med PMID 183579 06)

50. Results of Surgery for Colorectal Carcinoma with obstruction - Surgical Department, Didmotichon Gen. Hospital, Greece. Pub Med PMID : 18299883

51. Second line chemotherapy use in metastatic colon cancer varies by disease responsiveness. (University of Texas Health Science Center, Honston, TX, USA) Pub Med PMID : 18279578.

52. Chen VW, Fenoglio - Preiser CM, Wu $\mathrm{XC}$, et al. Aggressiveness of colon carcinoma in blacks and whites. national Cancer Institute Black/White Cancer 
Survival Study Group. Cancer Epidemiol Biomarkers Prev. 1997;6(12):1087-1093.

53. American Cancer Society. Cancer Facts \& Figures 2009. http:// wwwcancerorg/ downloads/STT/500809 web pdf. Accessed November 10,2009. 